\section{Edycaçäa

ARTIGO

\section{Editora}

Maria Inês Côrte Vitoria

PUCRS, RS, Brasil

\section{Editora Colaboradora}

Pricila Kohls dos Santos

PUCRS, RS, Brasil

\section{Equipe Editorial}

Carla Spagnolo

PUCRS, Brasil

Rosa Maria Rigo

PUCRS, Brasil

\title{
Formação inicial do pedagogo que atua como coordenador pedagógico: análises e reflexões dos saberes profissionais
}

\author{
Initial formation of the pedagogue who works as a pedagogical coordinator:
} analysis and reflections of professional knowledge

\section{ISSN 2179-8435}

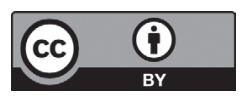

Este artigo está licenciado sob forma de uma licença Creative Commons Atribuição 4.0 Internacional, que permite uso irrestrito, distribuição e reprodução
em qualquer meio, desde que a publicação original seja corretamente citada. http://creativecommons.org/licenses/by/4.0/deed.pt BR
Susana Soares Tozetto ${ }^{1}$ Priscila Gabriele da Luz Kailer²

\section{RESUMO}

O presente artigo analisa os saberes da formação inicial do Pedagogo que atua como coordenador pedagógico na escola. O cotidiano desse profissional, imerso por acontecimentos imprevisíveis, mobiliza saberes a cada nova situação. Portanto, apresentamos como objetivo central discutir os saberes específicos do coordenador pedagógico. Os principais autores que sustentam as análises aqui propostas são Tardif (2002), Gauthier (1998), André e Vieira (2007) e Gimeno Sacristán (1999). Assim, foi feito uma análise documental do Projeto Político Pedagógico do curso de Pedagogia da Universidade Estadual de Ponta Grossa-PR entre os anos de 2007 a 2010 e entrevistas com seis egressos do curso que atuam na escola pública municipal como coordenador pedagógico. Os resultados mostram que a amplitude dos saberes do coordenador pedagógico desafia as possibilidades de formar um profissional para diversas funções, como docente, gestor e pesquisador.

Palavras-chave: Formação inicial; Saberes; Coordenador pedagógico.

\section{ABSTRAC}

This article analyzes the knowledge of the initial formation of the Pedagogue who acts as pedagogical coordinator in the school. The daily life of this professional, immersed by unforeseeable events, mobilizes knowledge with each new situation. Therefore, we present as a central objective to discuss the specific knowledge of the pedagogical coordinator. The main authors that support the analyzes proposed here are Tardif (2002), Gauthier (1998), André and Vieira (2007) and Gimeno Sacristán (1999). Thus, a documentary analysis of the Pedagogical

\footnotetext{
1 Doutora em Educação pela UNESP/ARARAQUARA. Docente associada da Universidade Estadual de Ponta Grossa no Departamento de Educação e no PPGE em Educação.

2 Mestre em Educação pela UEPG. Docente da Prefeitura Municipal de Ponta Grossa.
} 
Political Project of the Pedagogy course of the State University of Ponta Grossa-PR between the years of 2007 to 2010 and interviews with six students of the course that work in the municipal public school as pedagogical coordinator. The results show that the breadth of knowledge of the pedagogical coordinator challenges the possibilities of forming a professional for different functions, such as teacher, manager and researcher.

Keywords: Initial training; Knowledge; Educational coordinator.

\section{Introdução}

$\mathrm{O}$ entendimento da educação como um vetor fundante da modernidade colocou o profissional do ensino em um espaço central e, consequentemente, a sua formação para exercer a profissão conforme os ideários modernos. Apesar da formação de professores não ser uma preocupação recente, a temática obteve centralidade nas últimas décadas em virtude das exigências sobre ela. Novas responsabilidades foram atribuídas ao docente decorrente do projeto neoliberal de sociedade e das demandas que a universalização do ensino proporcionou.

Frente ao contexto, ressaltamos a importância de uma formação que ofereça uma bagagem sólida de saberes específicos do trabalho do coordenador pedagógico, que, para tanto, volte seu olhar aos processos educacionais, sem distanciar do âmbito escolar e dos saberes que norteiam a prática pedagógica. Assim, pontuamos que o curso de Pedagogia se constitui em espaço privilegiado para essa formação, o qual possibilita condições de problematizar a prática pedagógica e de constatar/discutir a lógica ideológica, política e pedagógica que marca o trabalho na sociedade capitalista (PABIS, 2014).

O papel do coordenador pedagógico não é neutro, considerando que há sempre um posicionamento presente na prática pedagógica que pode realizar tanto a transformação como a confirmação do status quo. Apesar do consenso legal sobre a importância dos saberes pedagógicos para a atuação do coordenador, segundo Pabis (2014), esse profissional permanece como guardião das políticas educacionais, ou seja, como um profissional que se demonstra mais preocupado em implementar as políticas educacionais na escola do que necessariamente voltar-se ao processo de ensino e de aprendizagem.

Ao tratar do rigor científico do trabalho do coordenador pedagógico, os saberes específicos devem ser apropriados no âmbito da formação especializada desse profissional. É a formação inicial que possibilita bases para o coordenador realizar seu trabalho de forma autônoma e consciente sobre sua prática, sem cair nas ações imediatas e fragmentadas, e, consequentemente, na perda da dimensão totalitária de sua função. Nessa perspectiva, defendemos a necessidade 
de o coordenador pedagógico ser formado em um curso de Pedagogia com consistência teórica, que possibilite a compreensão dos determinantes sociais, políticos e econômicos da educação.

Para o presente artigo, apresentamos como objetivo central discutir os saberes específicos do coordenador pedagógico com base em Gauthier (1998), Tardif (2002) e André e Vieira (2007). Sendo assim, enfocamos a formação inicial do coordenador pedagógico da Universidade Estadual de Ponta Grossa-PR (2007-2010), com a análise da reformulação e da elaboração do Projeto Político Pedagógico (PPP) da Licenciatura em Pedagogia. No bojo do texto, discorremos também sobre as etapas da investigação (KAILER, 2016), nas quais apontamos o campo, os sujeitos, os instrumentos e a análise dos dados investigados. E por fim apresentamos os resultados da pesquisa que envolve os saberes do coordenador pedagógico.

\section{Formação inicial do coordenador pedagógico}

A tendência assumida nas Diretrizes Curriculares Nacionais do Curso de Pedagogia (BRASIL, 2006), após a militância realizada pelo movimento dos docentes a favor de integrar a formação dos Anos Iniciais do Ensino Fundamental e da Educação Infantil no âmbito universitário, estabeleceu no Art. 10 a extinção das habilitações dos cursos de Pedagogia. Assim, assume o entendimento da formação do pedagogo com base na docência e não mais na formação do especialista.

Apesar dos avanços no curso de formação do Pedagogo, ressaltamos a necessidade de repensar sobre o significado da atuação docente e pedagógica do profissional na escola. Ao elaborar o curso de Pedagogia em uma formação de quatro anos que atende para além da atuação docente, como também no âmbito da gestão e na formação para a pesquisa, corre-se o risco de um formato aligeirado e abrangente para a formação do pedagogo. Ao considerar essa formação abrangente, destacamos, ainda, sobre o acréscimo de diferentes temáticas, indicadas pelas Diretrizes Curriculares Nacionais, entre elas: Educação no campo, Educação Inclusiva, Educação em espaços não-formais, entre outras.

A configuração do curso proposta nas DCN (BRASIL, 2006) modificou os antigos moldes de formação e trouxe alterações para as instituições, como a elaboração de novos Projetos Políticos Pedagógicos. Nesse contexto, o curso de Pedagogia da Universidade Estadual de Ponta Grossa elaborou o seu PPP, sendo que nesta pesquisa investigamos as alterações ocorridas com vigência nos anos de 2007 até 2010, considerando que o foco da pesquisa é discutir os saberes específicos do coordenador pedagógico. Nesse sentido, vemos a importância da formação inicial, pois ela se configura como o primeiro passo para o desenvolvimento profissional contínuo. Para isso, é preciso fornecer relações reais de diálogo com a prática social - uma prática comprometida, que se coloca além do aspecto da transmissão. 
A formação para a docência está pautada por conhecimentos que estão além do espaço de sala de aula. Assim, amplia-se o olhar do docente, que, conforme as DCN (BRASIL, 2006), compreendem a participação na organização e na gestão de sistemas e de instituições de ensino, configurando uma hierarquia que coloca à docência como hegemônica, ou seja, como base do processo formativo, seguindo-se o conceito de gestão e finalmente o de pesquisa. Desse modo, a concepção de docência proposta como base da formação do pedagogo, supõe um conceito alargado, que vai além da relação ensino-aprendizagem e compreende a gestão e a pesquisa.

O egresso do curso de Pedagogia da UEPG configura-se, portanto, um licenciado apto para atuar na docência como também na equipe gestora como: coordenador pedagógico ou diretor do sistema escolar. No que envolve o PPP do curso Pedagogia em análise (UEPG, 2006), os princípios pedagógicos para a formação do docente e do gestor encontram-se associados. Assim, o documento pontua à docência como ato educativo intencional, entendido em seu sentido amplo, como trabalho e processo pedagógico. A fim de realizar a análise documental do PPP do curso, apoiamo-nos em Lüdke e André (1986) que pontuam sobre a contribuição desse instrumento, que possibilita tanto a exploração de aspectos novos de uma dada pesquisa como também a complementação de outras técnicas de investigação. Lüdke e André (1986) afirmam que a etapa final da análise documental ocorre quando a exploração dessa fonte se torna redundante ou há um acréscimo insignificante de informações.

Para a análise documental do PPP do curso (UEPG,2006), primeiramente ressaltamos as disciplinas articuladoras, tendo em vista a importância que elas representam ao possibilitar tempo e espaço para realizar processos de observação, problematização e análise, na compreensão do trabalho pedagógico em um dado contexto histórico, social, cultural e organizacional. As disciplinas articuladoras chamadas de Pesquisa e Pratica Pedagógica se realizam durante os quatro anos de formação do pedagogo e tem a função de articular teoria e pratica no decorrer de todo o curso.

As disciplinas articuladoras de Pesquisa e Prática Pedagógica, que, de acordo com o PPP do curso (UEPG, 2006), tem como um dos objetivos proporcionar a problematização do estágio, com as referências teórico-pedagógicas já incorporadas das disciplinas anteriores, para refinar o projeto de pesquisa que culmina com o trabalho de conclusão de curso. Nesse enfoque, busca-se, também, uma relação entre os diferentes saberes e, o estágio deixa de ser restrito a um espaço meramente técnico e prático e passa a obter um caráter de formação coletiva, que se desenvolve em consonância com a escola, a universidade (UEPG, 2006). O futuro pedagogo deixa de ser entendido como um acessório do curso e passa a ser valorizado como um elemento chave para a construção da identidade profissional.

Ainda, no terceiro ano do curso, outra disciplina articuladora, Seminários Avançados em Gestão (UEPG, 2006), visa favorecer a aproximação do acadêmico com o trabalho do pedagogo na escola, em sua dimensão de gestão nos diferentes níveis de ensino. Para tanto, busca articular os conhecimentos das disciplinas da formação com o 
trabalho do pedagogo na gestão da escola (UEPG, 2006). Assim, a realidade da organização escolar e das relações pedagógicas é enfocada a partir dos eixos de trabalho do pedagogo na escola: político-administrativo, pedagógico e humano (UEPG, 2006). De acordo com Pabis (2014), a formação da consciência faz-se a partir da realidade social. No entanto, não se trata de qualquer realidade, é preciso uma realidade comprometida, problematizada e pensada. Assim, o espaço dessa disciplina na formação possibilita a compreensão do trabalho do pedagogo, na qualidade de coordenador pedagógico e diretor do espaço escolar.

Ainda, Seminários Avançados realizam um processo sistemático de indagação e reflexão sobre as questões relacionadas ao ensino, seus condicionantes sociais, políticos, econômicos e culturais, bem como à gestão educacional e à organização do trabalho pedagógico na escola (UEPG, 2006). Conforme o PPP do curso (UEPG, 2006), essa disciplina denota um espaço para reflexão e problematização a partir de momentos de sistematização e síntese da relação teórico-prática.

Entendemos a necessidade de a licenciatura em Pedagogia fornecer espaço de discussão que vise compreender os condicionantes que envolvem o trabalho do coordenador pedagógico, tendo em vista que, no cotidiano da escola, esse profissional é marcado por determinantes sociais, políticos, econômicos, culturais que interferem na sua atuação. Pabis (2014) também aponta a necessidade de os profissionais do ensino, inclusive o coordenador pedagógico, conhecer os determinantes que envolvem a escola e como eles se articulam, a fim de obter condições para planejar, pensar e realizar seu trabalho de forma consciente.

O PPP (UEPG, 2006) também pontua que não há como conceber a formação inicial desse profissional sem o exercício de reflexão e de indagação sobre a realidade. Para tanto, os referenciais que embasam as disciplinas articuladoras do curso (UEPG, 2006) estão em consonância com a perspectiva da prática reflexiva, em contraponto ao modelo da racionalidade técnica, que hierarquiza e distancia a teoria da prática. Cabe considerar no PPP (UEPG, 2006) que as disciplinas articuladoras do curso não restringem a reflexão ao estágio, ao contrário, inserem a integração e a articulação de todas as disciplinas do curso, a problematização do estágio, como também as discussões que se inserem nesse espaço de articulação.

$\mathrm{Na}$ formação do gestor e do coordenador pedagógico, denotamos a importância das discussões que permitem um entendimento sobre o escopo mais amplo do trabalho realizado na escola. Essa discussão será retratada nas disciplinas de Gestão Educacional I e II. Não se trata de minimizar as questões que envolvem a sala de aula, mas de compreender que há especificidades no trabalho do coordenador pedagógico que precisam estar fundamentadas na formação inicial desse profissional. O coordenador pedagógico realiza seu trabalho tanto no suporte ao trabalho do professor - procurando compreender as questões relativas à aprendizagem dos alunos de forma mais direta -, como também na organização do trabalho pedagógico da escola, que necessita de uma clareza de aspectos 
estruturais e organizacionais. Domingues (2014) afirma que a formação do coordenador pedagógico precisa estar alicerçada em termos conceituais e práticos para subsidiar o trabalho com os professores, com os alunos e com a comunidade.

As disciplinas de Gestão Educacional I e II, fundamentam o trabalho do futuro gestor com espaços de articulação entre os conhecimentos da escola, dos processos de ensinar e aprender e das práticas de gestão na perspectiva da pesquisa. Observamos uma preocupação de articular a docência, a gestão e a pesquisa, a fim de superar a fragmentação do curso nos eixos de formação. Entretanto, para Pabis (2014, p.89), “[...] o curso continua fragmentado, antes fragmentação entre a formação do professor e o especialista através das habilitações, atualmente a fragmentação entre o professor, o gestor e o pesquisador". Assim, a segregação é intensificada pela concepção ampliada de docência, que passa a estar integrada à gestão e, que dificulta a compreensão das especificidades da atuação da equipe gestora.

A disciplina Gestão Educacional I aborda a compreensão da escola "[...] como construção histórica, seus sujeitos e organização, suas relações de determinação pela política educacional e o entorno social" (UEPG, 2006, p.30). A disciplina de Gestão Educacional II contempla as discussões no segundo ano do curso e ressalta a avaliação institucional, o PPP e a formação continuada como processos pedagógicos centrais (UEPG, 2006).

É importante discutir no curso com as futuras pedagogas que o coordenador pedagógico é articulador do processo de ensino-aprendizagem na escola. Assim, esse profissional atua ao mesmo tempo dentro e fora da sala de aula, ao realizar o suporte ao professor ou na organização do trabalho pedagógico. No entanto, a atuação do coordenador pedagógico precisa estar em consonância com o modelo profissional apreendido no espaço da formação, tendo em vista que é nesse momento que acontece o desenvolvimento de sua profissão; caso contrário, corre-se o risco de realizar um trabalho pautado por questões imediatas que envolvem a escola. Nesse sentido, entende-se que o coordenador pedagógico precisa ter clareza da importância do seu trabalho e reconhecer as suas atribuições, com destaque para as ações que esse profissional desenvolve na formação continuada, na avaliação institucional, na elaboração coletiva do PPP. O referencial de Canário (2006), Ferreira (2003) e Nóvoa (2002) possibilitam discussões que envolvem especificamente o coordenador pedagógico e as atribuições desse profissional.

Passa a haver um profundo estudo investigativo sobre o cotidiano da escola e suas necessidades. Uma valorização dos aspectos sociais, políticos, econômicos e culturais passam a ser o ponto inicial da problematização do currículo na escola por parte do coordenador pedagogico. Predominam as ações pensadas criticamente e voltadas para a realidade escolar. Nesse sentido, emerge, dentre outras, a preocupação do coordenador pedagogico com a formação continuada dos docentes voltada para um trabalho de reflexividade critica (NÓVOA, 1995). A formação continuada 
deve estimular uma perspectiva crítica, reflexiva e problematizadora, que forneça aos docentes a possibilidade de um pensamento autônomo, criativo, colaborativo e formativo. Práticas de formação que tomem como referência a pesquisa e o estudo e contribuam para a emancipação profissional do coordenador pedagógico. A formação deve requerer a consolidação de uma ação do coordenador pedagogico, comprometida com os saberes necessários para uma atuação consciente por parte do docente em sala de aula.

O Estagio Curricular Supervisionado em Gestão Educacional contemplado no quarto ano de formação do pedagogo (UEPG, 2006), realizado na Educação Infantil, nos Anos Iniciais do Ensino Fundamental e no Ensino Médio, com as problematizações de conceitos e práticas, buscam a investigação da realidade educacional com elaboração de projetos de investigação e/ou ação no espaço escolar (UEPG, 2006). Para a formação do gestor e do coordenador pedagógico, é imprescindível o espaço/tempo que o estágio possibilita para aproximação real do trabalho desses profissionais. Destacamos no PPP (UEPG, 2006) as disciplinas de Gestão Educacional e Estágio Supervisionado em Gestão Educacional, a fim de compreender a formação do gestor e do coordenador pedagógico no referido curso e diferentemente das disciplinas pontuadas anteriormente, elas não se tratam de disciplinas articuladoras, mas se constituem no eixo curricular do curso.

O estágio caracteriza-se como um componente de constituição e desenvolvimento do ser profissional. É nesse espaço que o futuro profissional do ensino entra em contato com o trabalho do coordenador pedagogico na escola. Para tanto, é necessário uma postura diferenciada daquele que se realiza como aluno em sala de aula - é preciso problematizar a escola como parte constituinte de uma totalidade. No que envolve o PPP (UEPG, 2006) em análise, pontuamos que o estágio em gestão educacional se realiza no último ano do curso e acontece nas três etapas da educação básica, o que pode contribuir para a compreensão das especificidades que envolvem a organização do trabalho pedagógico nesses espaços.

A formação inicial voltada para a pesquisa configura-se como um importante avanço, já contemplado nas DCN (BRASIL, 2006) e que se reafirma no projeto do curso de licenciatura em Pedagogia da UEPG (2006). Aparece como um componente inovador no currículo do curso, sendo uma pratica fundamental para o desenvolvimento profissional do coordenador pedagógico.

É importante atentar para que a pesquisa realizada na formação inicial esteja voltada para a realidade, ou seja, retornada para a escola e seu cotidiano. Sendo assim, é admirável considerar e valorizar os sentimentos e saberes dos docentes no contexto da escola, da mesma forma que se pondera necessário em relação aos temas problematizados. Conforme Nóvoa (2002), o ofício de quem ensina, consiste basicamente em esquemas teóricos e práticos para conduzir a ação e para definir o componente intelectual do exercício profissional docente, fundante na pesquisa. 


\section{Os caminhos da pesquisa}

A formação inicial de Pedagogia da Universidade Estadual de Ponta Grossa/PR constitui-se como o campo de pesquisa deste trabalho. Ao considerar os contextos de atuação do coordenador pedagógico e a influência desses espaços no trabalho dos profissionais, delimitamos nesta pesquisa os coordenadores pedagógicos, egressos no ano de 2010 e que atuam nas escolas públicas municipais de Ponta Grossa, a fim de retratar de forma mais precisa a realidade dessa formação.

Após contato com os setenta seis (76) pedagogos na rede municipal de ensino de Ponta Grossa, encontramos seis (6) egressos do curso de licenciatura em Pedagogia da UEPG (2007 a 2010), que desenvolvem seu trabalho na coordenação pedagógica das escolas públicas municipais. Realizamos entrevista semiestruturada com os seis (6) coordenadores pedagógicos, três (3) estão atuando no Centros Municipais de Educação Infantil (CMEI), e outros três (3) encontram-se no espaço do Ensino Fundamental nos Anos Iniciais. Para caracterizarmos os coordenadores pedagógicos denominamos nesta pesquisa como CP1, CP2, CP3, CP4, CP5 e CP6.

Para compreender os saberes que emergem na formação inicial, utilizamo-nos da análise de conteúdo de Bardin (1977), que a autora caracteriza como “[...] um conjunto de técnicas de análise das comunicações” (BARDIN, 1977, p.33). No entanto, não se trata de um instrumento simples, mas de uma análise rigorosa, marcada por diferentes formas e adaptável a um campo vasto de aplicação, nesse caso as escolas municipais.

Os objetivos elencados por Bardin (1977) para realizar Análise de Conteúdo caracterizam-se na ultrapassagem da incerteza e no enriquecimento da leitura. Para tanto, foi feita uma leitura atenta, pautada pela rigorosidade e a necessidade de descobrir, de ampliar a compreensão sobre os saberes do coordenador pedagógico. Assim, a análise de conteúdo é uma técnica de investigação que, por meio de uma descrição objetiva e sistemática e tem por finalidade a interpretação da comunicação entre os sujeitos investigados (BARDIN, 1977).

Diante disso, a última etapa desta pesquisa está pautada na relação entre a análise do PPP (UEPG, 2006) e os dados coletados por meio de entrevista semiestruturada com os egressos do curso em análise. Os procedimentos de análises caracterizam-se por uma classificação de unidades e de significados, criando categorias "[...] introduzindo uma ordem suplementar reveladora de uma estrutura interna" (BARDIN, 1977, p. 55). Diante disso, as entrevistas foram analisadas rigorosamente e agrupadas de acordo com uma estrutura interna, em categorias de análise e de subcategorias. Destacamos neste trabalho a categoria: Formação inicial do coordenador pedagógico com a subcategoria saberes do coordenador pedagógico. 


\section{Saberes do coordenador pedagógico}

Ao tratar dos saberes, Tardif (2002) denota que o conjunto de processos formativos e de aprendizagens socialmente elaboradas, destinam-se a instruir os professores, e acontece ao longo do desenvolvimento profissional do mesmo. Para isso, cabe aos educadores que passam pela formação inicial, definir suas práticas em relação aos saberes que possuem e devem transmitir (TARDIF, 2002). Entretanto, o escopo dos saberes deixa de ser entendido como elemento exclusivo dos docentes e envolve o grupo de educadores como um todo, incluindo o coordenador pedagógico como o profissional responsável na organização do trabalho pedagógico na escola.

Ao estabelecer as contribuições de alguns autores (TARDIF, 2002; GAUTHIER, 1998), demarcamos a necessidade de analisar os saberes da formação inicial que balizam o trabalho do coordenador pedagógico na escola. A formação do coordenador pedagógico está atrelada à formação do docente, e, desse modo, entendemos que a formação do pedagogo precisa considerar a dimensão teórico-prática da educação. Entretanto, os saberes apoiados em uma ciência pura permite ao coordenador pedagógico exercer sua profissão com fundamentação teórica consistente. Portanto, o conhecimento específico desse profissional não está restrito ao domínio do espaço de sala de aula, resolvendo os problemas encontrados na prática docente com a aplicação de um repertório de conhecimentos e soluções preestabelecidas. A ênfase teórica no curso de Pedagogia reconhece a importância da prática no processo de formação do coordenador pedagógico e busca a formulação de um saber de cunho científico que promova o interlace entre teoria e prática.

Frente ao contexto, buscamos em Tardif (2002) os saberes curriculares que constituem os discursos, métodos, objetivos e programas escolares, criando um processo de interdependência no qual os coordenadores pedagógicos cunham conhecimentos, imagens e atitudes que compõem a essência de seu trabalho. Os saberes curriculares apresentam-se sob a forma de programas escolares como por exemplo: objetivos, conteúdos, métodos que o coordenador pedagógico tem que conhecer para orientar os docentes em suas práticas de sala de aula. Isso significa, uma aprendizagem que mobilize saberes sobre currículo com solidez e com conhecimento sobre plano de ensino, grade curricular, plano pedagógico da escola, entre outros.

Tais saberes são importantes para a organização da escola e para oferecer aos docentes a estruturação dos conteúdos e os fundamentos teóricos e metodológicos das diferentes áreas de ensino. Segundo Tardif (2002, p. 220):

Em suma, a ordem escolar já oferece aos professores um quadro facilitador para estabelecer a ordem na sala de aula: antes mesmo de começar seu trabalho, antes mesmo de entrar numa sala de aula, um professor já possui um certo número de certezas quanto ao seu quadro habitual de trabalho. 
Assim, o docente ao assumir a regência da classe tem domínio de dispositivos ordenados em seus aspectos principais para o direcionamento das atividades com seus alunos. No decurso de seu trabalho, o docente necessita tomar decisões a respeito do que já está definido de antemão na escola, como por exemplo o ambiente físico, as relações sociais, entre outros fatores. Sendo assim, ele necessita do coordenador pedagógico para discutir, orientar para tais ações. O coordenador pedagógico oferece ao docente um quadro panorâmico para gerir o espaço de sala de aula e os condicionantes ligados à interação com os alunos.

Já Gauthier (1998), discute a gestão da matéria como uma função importante a ser desempenhada pelo docente. Ele remete a esse profissional os enunciados relativos ao planejamento do ensino, que reúne um conjunto de variáveis relativamente influentes na aprendizagem. Conforme o autor (1998, p. 198):

A organização do trabalho durante a fase de planejamento consiste na disposição de um conjunto de tarefas que visam, por exemplo, determinar os objetivos de aprendizagem, bem como priorizar e transformar os conteúdos em correspondência com os objetivos. [...] A organização do ambiente educativo (tempo, lugar, material, recursos), a seleção das estratégias de ensino e das atividades de aprendizagem apropriadas, a seleção das sequencias de atividades, a especificação dos procedimentos de avaliação preocupam igualmente os professores.

Nesse sentido, cabe ao coordenador pedagógico na escola, subsidiar os docentes em suas dúvidas, dificuldades e necessidades quanto a gestão da matéria. A maioria das decisões a serem tomadas pelo mesmo, requer direcionamento do coordenador pedagógico para uma prática coerente com o planejamento dos objetivos do ensino de forma ampla na escola.

Constata-se também a importância do coordenador pedagógico nas ações da avaliação, da interação com os alunos, no planejamento de estratégias da escola como um conjunto. Portanto, para obter êxito em seu trabalho, se faz necessário um trabalho coletivo, isto é, em conjunto e em comum acordo com os docentes da escola. A gestão de pessoas, com viés democrático, só pode ser uma realidade quando as ações ultrapassam o âmbito do discurso e se efetivam na escola sustentadas nos princípios dialógicos e na alteridade. O modo como o coordenador pedagógico mobiliza os saberes no cotidiano da escola denota os sentidos e os significados que as ações são realizadas no espaço da escola. Ou seja, ao privilegiar determinada atuação, o coordenador pedagógico estabelece os saberes que serão mobilizados.

Assim, os saberes constituídos no processo de profissionalização do coordenador pedagógico estão embasados por uma epistemologia da ciência que fundamenta seu trabalho. Gauthier (1998) denomina, como o saber das 
ciências da educação, um conjunto de saberes adquiridos no processo de formação do professor, que nem sempre está diretamente relacionado às ações do coordenador pedagógico, mas que direciona e fundamenta seu trabalho. A seguir, a coordenadora pedagógica aponta os saberes da ciência como pano de fundo no trabalho do coordenador pedagógico, ao relatar a importância da filosofia para compreender o ser humano:

"Teve aula que era muita teoria, mas aula de didática dava para fazer essa junção com a sala de aula, aula de gestão, até a própria aula de Filosofia, não com a escola, mas como lidar com o ser humano." (CP2)

Entretanto, os saberes que envolvem o coordenador pedagógico são multifacetados e não se limitam aos saberes das ciências, e nem tão pouco aos saberes da gestão da matéria. Há, ainda, os saberes profissionais, éticos, políticos, relacionais, entre outros, que se manifestam no cotidiano do trabalho do coordenador pedagógico. A dicotomia teoria e prática da formação do coordenador pedagógico interfere no modo como os saberes vão se relacionar durante sua atuação, os quais acabam se sobrepondo de acordo com o processo de profissionalização. Assim, os saberes do coordenador pedagógico não são apreendidos no vazio, o coordenador mobiliza saberes de acordo com sua trajetória pessoal e profissional. A coordenadora pedagógica entrevistada coloca a importância da trajetória na escola para a mobilização de saberes na função que exerce:

"É fundamental a experiência para o coordenador, porque ele tem que passar pela sala de aula, por vários segmentos e por várias modalidades, Educação Infantil, EJA, Ensino Fundamental. Porque, senão, você não tem uma prática certa." (CP5)

Assim, a atuação do professor em sala de aula é um importante espaço para mobilizar saberes, definir estratégias e legitimar práticas pedagógicas para o trabalho do coordenador pedagógico. Com esse entendimento, Gauthier (1998) elege o saber experiencial como um espaço/tempo privilegiado do profissional da educação, o qual busca mecanismos para sua prática pedagógica e a reproduz de acordo com as necessidades. O saber adquirido durante a trajetória das coordenadoras pedagógicas na qualidade de professoras, em atuação em sala de aula, é reconhecido também pela entrevistada como um componente importante para orientar o trabalho dos professores:

"Sem a experiência pedagógica de sala de aula, eu jamais conseguiria orientar as minhas professoras como eu oriento agora. Porque não adianta querer orientar uma coisa que você não sabe fazer." (CP6) 
Ao compreender o coordenador pedagógico como parte integrante da equipe docente, defendemos que sua atuação possui como fim o processo de ensino e aprendizagem dos alunos. Assim, os saberes da experiência tornam-se um mecanismo para o coordenador pedagógico compreender o trabalho docente e intervir quando necessário. Dessa forma, a experiência em sala de aula não ganha sentido em si mesma, é preciso estar relacionada a outros saberes. Gauthier (1998) elucida que a experiência tem característica privada, ou seja, individualmente o docente reproduz e elabora sua própria jurisprudência. Para o autor, o aspecto privado das experiências, bem como a falta de verificação por meio de métodos científicos, limita o saber na medida em que ele se basta com argumentos e pressupostos. No relato seguinte, a coordenadora pedagógica coloca a importância de compreender a realidade da sala de aula:

"Se eu chego, no caso, e assumo uma coordenação sem a vivência em sala de aula, eu não ia saber a realidade como que é." (CP3)

É inegável que o coordenador pedagógico precisa compreender aspectos da docência, tendo em vista que cabe a esse profissional a responsabilidade de subsidiar o trabalho docente. Contudo, para além da esfera da docência, o coordenador pedagógico carece de domínio dos demais procedimentos que envolvem a organização do espaço escolar. Desse modo, a prática em sala de aula não se realiza de forma desligada; pelo contrário, está correlacionada à dinâmica curricular, ao Projeto Político Pedagógico e ao desenvolvimento profissional do professor. Com essa premissa, afirma-se que, para refletir sobre o seu fazer, o coordenador pedagógico precisa estar alicerçado a uma sólida formação em termos conceituais e práticos.

Além de destacar os saberes da experiência para dar suporte à atuação do coordenador pedagógico, as entrevistadas salientam que o embasamento teórico e prático se torna uma maneira de comprovar os saberes do trabalho desenvolvido:

“Agora, é aquela questão que eu te falei de ser testado né, então, as pessoas vão te testar para ver até onde vai o teu conhecimento." (CP4)

"Quando você tem a experiência em sala de aula você prova por $A+B$ que dá certo, então é importante você passar por sala de aula." (CP5)

A experiência docente e o arcabouço teórico tornam-se, assim, critérios para legitimar o trabalho realizado pelo coordenador pedagógico, que passa a ser reconhecido, assim como a trajetória profissional em sala de aula ou dos conhecimentos adquiridos no processo formativo. Gauthier (1998) aborda que o repertório de conhecimentos 
específicos contribui para definir o status profissional; assim, defendemos que, do mesmo modo que é necessário um repertório de conhecimentos para ensinar, também se torna indispensável um arcabouço de saberes específicos do trabalho do coordenador pedagógico.

Sendo assim, Pinto (2011) destaca que não basta ao coordenador pedagógico ter experiência em sala de aula, é preciso obter saberes que envolvem a organização sistêmica da escola, teorias de currículo, políticas públicas na área de educação escolar, avaliação dos processos de ensino e aprendizagem, entre outros saberes que envolvem a atuação do coordenador pedagógico e que ultrapassam os saberes da experiência em sala de aula.

A universidade, como espaço de formação e de legitimação dos saberes, precisa compreender os aspectos centrais do trabalho dos profissionais que pretende formar. Cabe pontuar que se a concepção do coordenador pedagógico, já no processo formativo, encontra-se fragmentada ou dispersa, isso terá consequência no desenvolvimento de seu trabalho na escola. Nesse sentido, a fala a seguir pontua sobre a dificuldade em reconhecer o trabalho do coordenador pedagógico na formação inicial:

"No curso, eu não conseguia perceber o trabalho do coordenador pedagógico, eu não me reconhecia neste trabalho [...]. Inclusive nos primeiros meses como coordenadora eu me via voltando para a sala de aula." (CP4)

O reconhecimento do saber específico do futuro profissional manifesta-se no processo de formação inicial. Gauthier (1998) pondera que a definição de profissão exige, dentre outras características, uma competência como produto de uma formação específica. Com isso, o pertencimento a um grupo profissional requer a apropriação de um conhecimento sistematizado, que se realiza na formação do profissional nos espaços universitários. Desse modo, o trabalho que o coordenador pedagógico exerce na escola está atrelado aos saberes adquiridos na formação inicial. No relato a seguir, a coordenadora pedagógica pontua sobre a importância do curso de Pedagogia no trabalho que realiza na escola:

"Eu nunca tinha trabalhado em escola e foi lá que eu aprendi tudo. Não me acho diferente de uma pessoa que teve Magistério, eu não tive Magistério. Tudo que eu aprendi foi na Pedagogia como organização pedagógica, metodologia, planejamento. A base para o trabalho que realizo hoje, eu tive no curso. Quando eu cheguei na Prefeitura, eu não tive alguém para me orientar, eu não sabia nem preencher um livro de chamada, ninguém me ensinou e eu não tinha experiência em escola, eu aprendi lá no curso de Pedagogia, nos estágios e nas disciplinas." (CP2) 
No que tange os saberes teórico-práticos do coordenador pedagógico, Gimeno Sacristán (1999, p. 33) corrobora que a ação de um agente é dotada "[...] de sentido, de significados e de valor; algo que se empreende por alguma razão e que tem um fim". Nesse sentido, cabe a formação inicial discutir temas e promover ações pedagógicas que ultrapassem a perspectiva de aplicação de técnicas ou de teorias sobre educação.

Segundo Ferreira (2011), os saberes não se esgotam no saber fazer e no saber o que ensinar, é preciso ressaltar o saber articulador e o trabalho orgânico para a verdadeira qualidade do trabalho pedagógico. Destacamos nos relatos a seguir o saber co-participativo, democrático que está presente na atuação do coordenador pedagógico:

"Eu fazia parte da equipe dos professores quando fui convidada para assumir como coordenadora pedagógica. Foi complicado em relação às amizades com as outras professoras, pois você não é mais apenas colega das professoras, tive que tomar outra postura. Às vezes eu tenho que dar uma orientação, e, em outras, eu tenho que lembrar algumas normas e as professoras podem não gostar. Então, eu tentei encontrar maneiras de conversar com elas, de me relacionar de forma diferente. Buscando sempre resolver os problemas de maneira coletiva." (CP1)

“É preciso saber lidar com as pessoas, para conviver no trabalho com os diferentes pensamentos. No que envolve os conflitos por exemplo é preciso ter calma, compreender que as pessoas não são todas iguais, isso foi coisas que eu aprendi no curso de Pedagogia e no cotidiano da escola." (CP2)

O trabalho do coordenador pedagógico não se restringe aos aspectos burocráticos, quando reconhece e realiza funções que envolvem a orientação, a formação continuada e a elaboração do PPP. Essas ações requerem um trabalho coletivo em situações interativas com a comunidade escolar, que, desse modo, se realizam na busca de construir um espaço democrático na escola. Assim, concordamos com Tardif (2002) que os saberes ultrapassam as experiências individuais, que, para o autor envolvem o trabalho co-participativo, de parcerias e experiências adquiridas em diferentes espaços coletivos.

Tardif (2002) também pontua que as ações empreendidas pelo profissional da educação estão carregadas de histórias e que, nesse sentido, refletem nas atuações que se realizam na escola, podendo, assim, obter um caráter democrático ou não. Os saberes são, acima de tudo, sociais e se modificam e se adaptam nas ações do coordenador pedagógico. Tal pensamento compreende que os saberes são construídos, reconstruídos e mobilizados de acordo com as necessidades profissionais do professor e, do mesmo sentido, do coordenador pedagógico.

Outro aspecto fundamental entre os saberes do coordenador pedagógico, diz respeito ao saber curricular é colocado como imprescindível para o trabalho que realiza na escola. No entanto, a entrevistada acentua que esse saber foi pouco aprofundado no curso de Pedagogia o que gerou dificuldades em seu trabalho: 
“Alguns saberes não foram tão trabalhados no curso e eu considero relevante no meu trabalho na escola, como o currículo que poderia ser mais aprofundado. É preciso um currículo diferenciado para a educação infantil, e isso não foi muito aprofundado no curso. E esse conhecimento me fez falta. As vezes, na graduação, o acadêmico até pensa que é bom quando o professor não dá muito trabalho, mas depois você percebe que alguns conhecimentos fazem muita falta." (CP1)

Domingues (2014) acentua o coordenador pedagógico como aquele que orienta a organização curricular e o desenvolvimento do currículo. Para tanto, esse profissional precisa obter saberes curriculares para realizar a assistência direta aos professores na elaboração dos planos de ensino, nas práticas de avaliação da aprendizagem, na formação continuada, nas práticas pedagógicas, entre outras atribuições que lhe são pertinentes.

O coordenador pedagógico, evidentemente, tem que conhecer sobre teorias de currículo para planejar e avaliar no processo de ensino e aprendizagem. Sendo assim, conhecer o programa oficial da escola é um ato essencial para exercer a função de orientar os professores em sala de aula. De fato, compete ao coordenador pedagógico a escolha, seleção e organização dos saberes produzidos pela ciência e os transformar em conhecimento escolar que será ensinado as crianças. Sabe-se igualmente que professores e coordenadores pedagógicos necessitam de uma série de saberes, em parte devido as transformações da sociedade, fazendo-se fundamental um estudo contínuo para dar conta do currículo na escola.

Todavia, é preciso considerar que as ações de formação continuada e orientação que o coordenador pedagógico realiza na escola não devem limitar-se aos saberes curriculares, incluindo assim no seu trabalho a realidade da escola e sua cultura organizacional (PINTO, 2011). Ao realizar suas atribuições, o coordenador pedagógico precisa mobilizar o saber formador, conforme colocado a seguir:

"A formação continuada eu faço na hora atividade com a leitura e discussão. Não há tempo disponível, então eu aproveito a hora atividade. Eu divido o planejamento em três momentos: para fazer o planejamento, para preparar o material que vai ser usado nas aulas e para as discussões." (CP1)

"Na escola, é preciso uma formação mediada pela equipe gestora, deveria haver sempre uma formação. Momentos de aprender e refletir sobre a sua prática e do outro, mas não tem tempo." (CP2)

Segundo Nóvoa (1995), a formação continuada possibilita o desenvolvimento pessoal para a vida do professor, o desenvolvimento profissional para a profissão docente e o desenvolvimento organizacional com a finalidade de atender as necessidades da escola. Assim, a formação continuada é parte integrante de um amplo processo formativo, 
que abrange aspectos históricos, culturais e sociais do profissional da educação. Desse modo, a escola configura-se como lócus de formação permanente desse sujeito.

Cabe ao coordenador pedagógico articular e mobilizar o saber formador a fim de realizar a formação continuada de forma coletiva e colaborativa. Nessa medida, ao realizar a formação continuada, valoriza-se os conhecimentos docentes, contribuindo para a construção do coletivo escolar. Nesse sentido, o coordenador pedagógico assume a função de articulador, problematizador e mediador na organização da formação continuada no espaço escolar, por meio de referenciais teóricos e uma postura baseada na cooperação, na alteridade e no diálogo, a qual permite que o professor assuma o processo de construção da sua profissão, como protagonista.

Deste modo é necessário que o coordenador pedagógico assuma o processo de formação continuada na escola, como articulador principal. É de salutar importância esse trabalho na escola, pois será através desse processo formativo que os docentes aprimoram os saberes de caráter pedagógico e ampliam sua visão sobre o ensinar e o aprender. Propõe-se como um grande passo para que se garanta a melhoria da qualidade da educação, sendo válido ressaltar que a escola de tempo integral, tem previsto um acompanhamento, por parte do coordenador pedagógico, aos docentes. Para esse tipo de escola, temos um tempo ampliado na permanência dos docentes, favorecendo um cotidiano que reserva tempo no interior da instituição, para aprimorar o trabalho com os aspectos pedagógicos e curriculares.

Ao apresentar os saberes do coordenador pedagógico, André e Vieira (2007) ressaltam o cotidiano desse profissional, que, imerso por acontecimentos imprevisíveis, mobiliza saberes a cada nova situação. Com base nas autoras, evidenciamos que, no trabalho do coordenador pedagógico, se faz necessário saberes para realizar ações que envolvem o planejamento da rotina escolar, o acompanhamento do profissional docente, o atendimento de alunos e de pais.

Os saberes que envolvem o trabalho do coordenador pedagógico não se manifestam de forma individual. Segundo André e Vieira (2007), no cotidiano da escola, os saberes também são mobilizados nas relações que se estabelecem com professores, alunos e pais. Nesse sentido, são saberes que são produzidos nas suas relações com o outro, das mediações, das orientações, das resoluções dos conflitos, entre outras ações que visem a aprendizagem dos alunos.

O coordenador pedagógico mobiliza saberes no cotidiano escolar, identificando seu trabalho como intencional, organizado, planejado e sistemático. André e Vieira (2007) acentuam que o saber que fundamenta o trabalho do coordenador pedagógico se mobiliza quando o profissional pensa, planeja, organiza, redimensiona, as próprias ações.

$\mathrm{O}$ relato a seguir pontua sobre a teoria que se faz presente nas atividades realizadas pelo coordenador pedagógico:

Educação Por Escrito, Porto Alegre, v. 9, n. 2, p. 361-379, jul.-dez. 2018 
"Porque tem muito da teoria que você vai precisar. E você vê, plenamente, a pessoa que tem um certo descaso com algumas questões, às vezes é por não conhecer. Então, é necessário, por exemplo, para o preenchimento de uma ata, saber o que é direito da criança, o que você vai cobrar, porque é uma questão familiar. Tem situações que você vai encaminhar para outros órgãos, mas não é você que vai tentar resolver, sabe? E você vê que a pessoa não domina a área. Daí você já tem que ficar mais atento. Porque numa equipe é o trabalho de todos que precisa ser estabelecido, e daí você precisa resolver esse tipo de situação se for necessário." (CP4)

Muitos são os desafios enfrentados no cotidiano do trabalho do coordenador pedagógico na escola, são processos complexos que exige a mobilização de um corpo denso de saberes e experiências para que se efetive a melhoria da qualidade do ensino e da aprendizagem na escola. Bem como se possa edificar uma ação pedagógica competente.

\section{Considerações finais}

Analisar a formação inicial do coordenador pedagógico torna-se uma tarefa árdua quando se coloca em vista as contradições presentes no processo formativo e, consequentemente, no trabalho desse profissional. Os contrassensos refletem um distanciamento das contribuições que foram construídas teoricamente sobre o trabalho do coordenador pedagógico, bem como no processo de formação e nas ações que esse profissional assume na escola.

O papel da formação inicial na preparação do coordenador pedagógico, para atuar com base nos saberes pedagógicos da escola é de fundamental seriedade. Embora se reconheça a formação inicial como um importante espaço de construção dos saberes do coordenador pedagógico, evidenciamos que a indefinição nas atribuições desse profissional na escola, se torna mais agravante quando se considera os modelos administrativos assumidos por esse profissional. O modelo que favorece o trabalho do coordenador pedagógico como aquele que administra problemas burocráticos dentro da escola, ora como especialista, ora como técnico, resulta em uma compreensão despedaçada do trabalho docente, um currículo técnico a ser aplicado e, como consequência uma educação deficitária e fragmentada.

Vale destacar que as atribuições que o coordenador pedagógico assume hoje, no trabalho da escola, vão além da organização do trabalho pedagógico. Muitas vezes são atribuições de outros profissionais, como do diretor e/ou do secretário da escola. Assim, mobilizar saberes e ações apreendidas no decorrer do processo formativo tornam-se irrelevantes já que, para exercer uma atuação sem planejamento e imediatista, basta obter os conhecimentos técnicos e operacionais. 
Nesse sentido, torna-se complexo compreender os saberes que envolvem a formação dos coordenadores pedagógicos, já que em alguns contextos de atuação se secundariza ações e saberes específicos do seu trabalho em detrimento de outras funções. Com isso, o perfil profissional do coordenador pedagógico o aproxima de um multitarefeiro, pois é responsabilizado em assumir atribuições de acordo com as demandas do espaço escolar.

Portanto, ao discutir os saberes específicos do coordenador pedagógico, torna-se fundamental perceber o contexto em que a escola esta imersa. Frente a problemas de uma sociedade neoliberal que não valoriza os saberes experienciais, co-participativos, curriculares e formadores que são destacados nas falas dos coordenadores pedagógicos entrevistados. Se a escola não toma como fundante, para o trabalho do coordenador pedagógico, compreender o espaço da sala de aula e realizar a orientação do trabalho pedagógico do professor, estudar os saberes fica sem sentido.

Da mesma forma, o estágio na formação inicial, quando pautado por uma prática comprometida, também se torna um momento chave para a mobilização de saberes. Permitem ao futuro pedagogo que vai atuar como coordenador pedagógico, abarcar as especificidades que envolvem o trabalho realizado tanto em sala de aula como na organização do trabalho pedagógico na escola.

A importância do coordenador pedagógico no processo de planejamento e organização do trabalho pedagógico na escola é fundamental, pois deverá firmar laços de compromissos com a qualidade da educação pública nesse país. Incorporar direitos a aprendizagem do aluno e admitir a importância do seu trabalho como um intelectual que desenvolve ações e ideias em relação aos próprios atos, bem como aquele que produz saberes sobre a educação.

\section{Referências}

ANDRÉ, M. E. D. A; VIEIRA, M. M. da S. O coordenador pedagógico e a questão dos saberes. In: ALMEIDA, L. R.; PLACCO, V. M. N. de S. (Org.). O coordenador pedagógico e questões da contemporaneidade. 2. ed. São Paulo: Loyola, 2007.

BARDIN, L. Análise de conteúdo. Lisboa: Edições 70, 1977.

BRASIL. Resolução no 1, de 15 de maio de 2006. Institui Diretrizes Curriculares Nacionais para o Curso de Graduação em Pedagogia, licenciatura. Diário Oficial [da] República Federativa do Brasil, Poder Executivo, Brasília, DF, 16 maio 2006. Seção 1, n. 92, p. 11-12. CANÁRIO, R. A escola tem futuro? Das promessas às incertezas. Porto Alegre: ArtMed, 2006.

DOMINGUES, I. O coordenador pedagógico e a formação continuada do docente na escola. São Paulo: Cortez, 2014.

FERREIRA, N. S. C. (Org.). A gestão da educação na sociedade mundializada: por uma nova cidadania. Rio de Janeiro: DpeA, 2003.

FERREIRA, N. S. C. Supervisão educacional: uma reflexão crítica. 15. ed. Petrópolis: Vozes, 2011. 
GAUTHIER, C. Por uma teoria da pedagogia. Pesquisas contemporâneas sobre o saber docente. Ijuí, RS: Unijuí, 1998.

GIMENO SACRISTÁN, J. Poderes instáveis em educação. Porto Alegre: ArtMed, 1999.

LÜDKE, M.; ANDRÉ, M. E. D. A. Pesquisa em educação: abordagens qualitativas. São Paulo: EPU, 1986.

NÓVOA, A. Formação de professores e profissão docente. In: NÓVOA, A. (Coord.). Os professores e a sua formação. Lisboa: Dom Quixote, 1995.p.13-33.

NÓVOA, A. Formação de professores e trabalho pedagógico. Lisboa: Educa, 2002.

PABIS, N. O trabalho do pedagogo na escola pública do Paraná. 2014. 197 f. Tese (Doutorado em Educação) - Universidade Tuiuti, Curitiba, 2014.

PINTO, U. A. Pedagogia escolar: coordenação pedagógica e gestão educacional. São Paulo: Cortez, 2011.

KAILER, P. G. L. Formação inicial do coordenador pedagógico: o egresso (2007-2010) da licenciatura em Pedagogia da Universidade Estadual de Ponta Grossa-PR. 2016. 183f. Dissertação (Mestrado em Educação) - Universidade Estadual de Ponta Grossa, Ponta Grossa, 2016.

TARDIF, M. Saberes docentes e formação profissional. Petrópolis: Vozes, 2002.

UEPG. Universidade Estadual de Ponta Grossa. Projeto Pedagógico - Curso de Licenciatura em Pedagogia. 2006. (Processo no 04820 de 10/08/2006 - aprovado em 05/12/2006 pelo Parecer CEPE no 159/2006 e Resolução CEPE no 130/2006). Ponta Grossa: UEPG, 2006.

Recebido em: outubro/2017

Aceito em: abril/2018

\section{Endereço para correspondência:}

Susana Soares Tozetto <tozettosusana@hotmail.com>

Carlos Gomes, 120 - Centro

84010-480, Ponta Grossa, PR, Brasil 